\title{
Two Nobel Prizes that Both Fight Starvation, Helicobacter Pylori and WFP
}

\author{
Peter Benno, Elisabeth Norin and Tore Midtvedt* \\ Department of Microbiology Tumour \& Cell Biology, Karolinska Institutet, Sweden
}

*Corresponding author: Tore Midtvedt, Department of Microbiology Tumour \& Cell Biology, Karolinska Institutet, Stockholm, Sweden.

Received Date: March 12, 2021

Published Date: April 6, 2021

\section{Opinion}

In 2020 the Nobel Peace prize was awarded to World Food Program (WFP) due to their important job in distributing food and fighting starvation all over the world. Fifteen years earlier the Nobel Prize in Physiology or Medicine was awarded for the discovery of the bacterium Helicobacter pylori. This bacterium - in its own way - actually also helps fight starvation. In 2018 it was estimated that across the world 821 million people were going hungry -124 million acutely so [1]. In order to reduce starvation and treat malnutrition WFP for many years have delivered so called food baskets. The actual size and composition of the food basket is closely tailored to local preferences, demographic profile, climate conditions, local coping capacity and existing levels of malnutrition and disease [2]. In 1982 Robin Warren and Barry J. Marshall unexpectedly discovered that inflammation in the stomach (gastritis) as well as ulceration of the stomach or duodenum (peptic ulcer disease) could be the result of an infection caused by a bacterium. In 2005 they jointly were awarded the Nobel Prize in Physiology or Medicine. The infection could be treated by antibiotics. The bacterium was named Helicobacter pylori (H. pylori).

But there is also another evolutionary aspect of the bacterium which is seldom discussed. Most likely H. pylori colonized Homo sapiens more than 60.000 years ago and has ever since been a part of the normal human microbiome [3]. Globally it is estimated that 4.4 billion people are colonized with an incidence of close to $90 \%$ in developing countries i.e. in parts of the world where there most often is a lack of food [4]. So - why should Helicobacter pylori, known to cause gastritis and peptic ulcerations be predominant in a population living in developing countries?
Nitrogen is an essential component of amino acids and urea. Amino acids are the building blocks of all proteins. When proteins are broken down in the body there is a risk that valuable nitrogen may be lost. Nitrogen removed from amino acids is excreted via several different routes. The most familiar path is in urine where most of the nitrogen is in the form of urea. Nitrogen is however also excreted in the feces. A normal diet in developed countries leads to production of approximately 6-8 grams of urea in the stomach and in saliva every day [5]. This is where H.pylori is important and leads to "recycling" of nitrogen. The bacterium degrades the urea in the stomach and integrates the nitrogen into its own proteins [6]. When H.pylori follows the intestinal contents and later dies longer down in the gastrointestinal tract the bacteria's proteins are absorbed leading to a recycling of nitrogen.

In WFP's food basket there is often 50-60 grams of protein per person per day. In 6 grams of urea there is appr. 3 grams of nitrogen which equals the same amount nitrogen found in appr.18 grams of diet protein. The majority of this is recycled -every day- due to H.pylori i.e. equaling 1/3 of protein-quantity in the WFPs basket. Historically the evolutionary H.pylori colonization of Homo sapiens most likely is part of "survival of the fittest" and might, as indicated, still play a crucial role for survival in parts of the world where starvation and malnutrition is a daily challenge. This goes to show that even though completely different the Nobel Prize winners from 2005 and 2020 both fight world-wide starvation.

\section{Acknowledgement}

None. 


\section{Conflict of Interest}

\section{No conflict of interest.}

\section{References}

1. Max Roser, Hannah Ritchie (2013) Hunger and Undernourishment.

2. https://www.wfp.org/wfp-food-basket\#: :text=When\%20people\%20 are $\% 20$ fully $\% 20$ dependent, $\% 2$ C $\% 2$ iron $\% 2$ C $\% 20$ iodine $\% 20$ and $\% 20$ zinc.

3. Linz B, Balloux F, Moodley Y, Manica A, Liu H, et al. (2007) An African origin for the intimate association between humans and Helicbacter pylori. Nature 445: 915-918.

4. James KY Hooi, Wan Ying Lai, Wee Khoon Ng, Michael MY Suen, Fox E Underwood, et al. (2017) Global Prevalence of Helicobacter pylori
Infection: Systematic Review and Meta-Analysis. Gastroenterology 153(2): 420-429.

5. Visek W (1982) The influence of urea hydrolysis and ammonia on animals. In: White EGH, Walton JR (eds.), Normal and induced changes in the gastro-intestinal microflora in man and animals with special regard to animal performance. International symposium, Oslo, Norway 25/26 September 1980. Verlag P Parey, Berlin, Hamburg, Germany, pp. 64-76.

6. Levitt DG, Levitt MD (2018) A model of blood-ammonia homeostates based on a quantitative analysis of nitrogen metabolism in the multiple organs involved in the production, catabolism, and excretion of ammonia in humans. Clin Exp Gastroenterol 2018:11: 193-215. 